\title{
A BIBLIOMETRIC STUDY OF ENVIRONMENTAL PROTECTION AND ECONOMIC DEVELOPMENT: REVEALING LINKS AND DYNAMICS
}

\author{
Nicolae PINTILIE ${ }^{a}$, Claudiu CICEA ${ }^{b}$, Corina MARINESCU ${ }^{c}$ \\ a,b,c Bucharest University of Economic Studies, Romania
}

\begin{abstract}
The purpose of this paper is to create an image of the relationship between environmental protection and economic development through specialized papers published between 2000 and 2019. In this way, this paper is based on the study and analysis of the literature published on this topic in the last 2 decades. The paper also discusses how policies and measures towards environmental protection can be integrated into the European body, with a considerable impact on human development. After the presentation of the methodology, the paper develops an analysis in time and space of the selected scientific papers, then an analysis of the keywords with their grouping on clusters, creating a map of them and highlighting the existing relationships. Among the most interesting results are: (1) a massive concentration of works in the last five years of the period considered in the analysis; (2) China is one of the countries with the largest contribution in terms of authors; (3) The keyword map is particularly useful in revealing the link between keywords in the analysed context: the relationship between environmental protection and economic development. Finally, the paper presents possible limits of the research, but also future directions of its development.
\end{abstract}

KEYWORDS: environmental protection, pollution, economic development, economic growth.

\section{INTRODUCTION}

Globally, there are a multitude of studies that bring out the fact that economists can play an important role in highlighting the optimal transition to a low-carbon economy and resource efficiency. Moreover, in the context of the annual growth of factors that generically describe the term "pollution", economists are a source of inspiration in highlighting the optimal use of limited resources in the environment, correlating production methods with factors that help to increase environmental protection.

At this point, it is becoming increasingly clear that the global community, over the past few decades, has followed a path of development that has dealt with superficial sustainability, often ignoring this aspect. In the context of climate change, we obtain increasingly conclusive evidence based on existing data that population-driven development leads to consequences with an impact on the environment, which also generate negative side effects. According to Pachauri (2008), if the existing concentration of carbon dioxide were to double, it is possible to see a decrease in Global GDP of between 1.5 and 20\%. Moreover, it has also been shown that the cost of carbon dioxide could increase in monetary terms on a scale between $\$ 10$ and $\$ 350$ / ton, while the real social cost of carbon dioxide will increase from $2 \%$ per year to $4 \%$ per year (Pachauri, 2008).

The rapid economic growth of recent decades has been accompanied by high energy consumption and environmental degradation. The growing demand for energy has led to the incessant use of fossil fuels, with a direct negative impact on the environment. In this way, high energy consumption

\footnotetext{
*Corresponding author. E-mail address: pintilienicolae15@stud.ase.ro
} 
as a result of development and living standards of the population has fully contributed to the increase in carbon dioxide emissions and of the environmental risk related to climate change.

Both, economic growth and economic development are closely linked to energy today. From 1975 to 2019, the European Union experienced a remarkable economic development, and a growth registering an average annual increase in GDP of 2.19\% (The World Bank, 2020). Knowing this constant economic growth, energy consumption has remained high from year to year to support all the activities, so based on the equivalent of energy in thousands of tons of oil, in the period 2009 2018, Europe has consumed on average in every year equivalent energy to 1117778 thousand tons of oil (Eurostat, 2020a). Although since 1990 the share of solid fossil fuels has decreased significantly in the European Union (from $6.9 \%$ in 1990 to $3.6 \%$ in 2000 , to $2.8 \%$ in 2010 and $2.4 \%$ in 2018) and sources of renewable energy increased their share in total (from $4.3 \%$ in 1990 to 5.3\% in $2000,8.8 \%$ in 2010 and $10.5 \%$ in 2018), the highest share in the structure of final consumption of energy in 2018 is owned by oil and petroleum products (36.7\%), followed by electricity (23\%) and natural gas (21.4\%) (Eurostat, 2020b).

\section{LITERATURE REVIEW}

Given the rapid economic development of the last decades, the processes of industrialization and urbanization worldwide have accelerated, more and more people preferring the city life, giving up the rural areas. In this way, the density of the urban population has increased considerably, which has led to an increase in energy consumption, on one hand, and on the other hand to considerable quantities of household waste, with a direct impact on the environment (Sun, Wang, Wang, \& Zhang, 2019).

The process of accelerated urbanization led to the development of the economy, so that the relationship between economic growth and environmental protection was carefully analysed by many specialists who had divided opinions, influenced by factors such as the geographical area studied or chosen ways in order to apply certain research methods.

On one hand, Youssef et al. (2016) analysed the relationship between environmental pollution and economic development in 56 countries and proved the existence of the correlation using the Kuznets curve, income inequality vs. economic growth. Similarly, Jalil and Mahmud (2009) highlighted a significant inverse relationship between GDP per capita and carbon dioxide emissions per capita, reinforcing researchers' claims that economic development profoundly affects the natural elements.

On the other hand, Dinda (2004) considered that there is no proven relationship between economic development and environmental protection, as different economic variables have different effects on environmental pollution. Moreover, Chandran and Tang (2013) conducted an empirical analysis on the relationship between economic development and environmental protection in Southeast Asia and did not find the inverse link between the two concepts for the geographical area under study taking into account the period between 1971-2008. Chao and Wang (2017) have systematically measured carbon dioxide emissions and environmental efficiency issues in China and highlighted that environmental protection measures have helped reduce the problems, but there is still room for significant improvement. However, they could not identify a simple linear relationship between economic development and environmental protection.

Ansuategi (2003) emphasizes that most of the time there is an inverse relationship between economic development and environmental protection for phenomena that occur locally and in the short to medium term. Access to safe drinking water or quality health services are urgent human needs and any threat to them tends to be immediately attributed to human activities. However, the impact of other pollution-related problems such as global warming harms people who are geographically but also temporarily far from the place of pollution and therefore tend to be ignored 
by polluters. As a result, in his opinion, it is important that in the analysis of the two terms discussed in this paper to clearly specify the spatial and temporal sphere.

Although there are divided opinions among researchers on the relationship between environmental protection and economic development determined by geographical location, economic phenomena and social phenomena manifested in recent decades, Sun et al. (2019) point out that with the intensification of environmental regulations, companies will inevitably update their processes and procedures towards capitalizing on new opportunities and gaining economic benefits, using new technologies to reduce emissions. In this way, increasing concerns for environmental protection can drive the process of innovation in clean technologies, closely related to the capitalization of economic aspects, which is subject to the interests of all existing companies.

\section{ENVIRONMENTAL PROTECTION IN EUROPE: HOW TO INCREASE DEVELOPING THROUGH ENVIRONMENT CARE}

The effects on the environment of energy production, transport and individual use are different and significant. These range from soil and water contamination from the extraction and transport of fossil fuels, to emissions of local air pollutants and greenhouse gases from the burning of fuels, and finally to radiation from the improper storage of nuclear waste.

At the level of the European Union, the economic development of the last years has been correlated with the change of the weights of the means of energy production, with an increase from year to year of the energy produced from renewable sources. In fact, according to the World Bank, as can be seen in Figure 1, at the level of the European Union there was an average annual increase in GDP of about $2.19 \%$, while the share of renewable energy sources in total energy in the Union was $10.5 \%$ in 2018 .

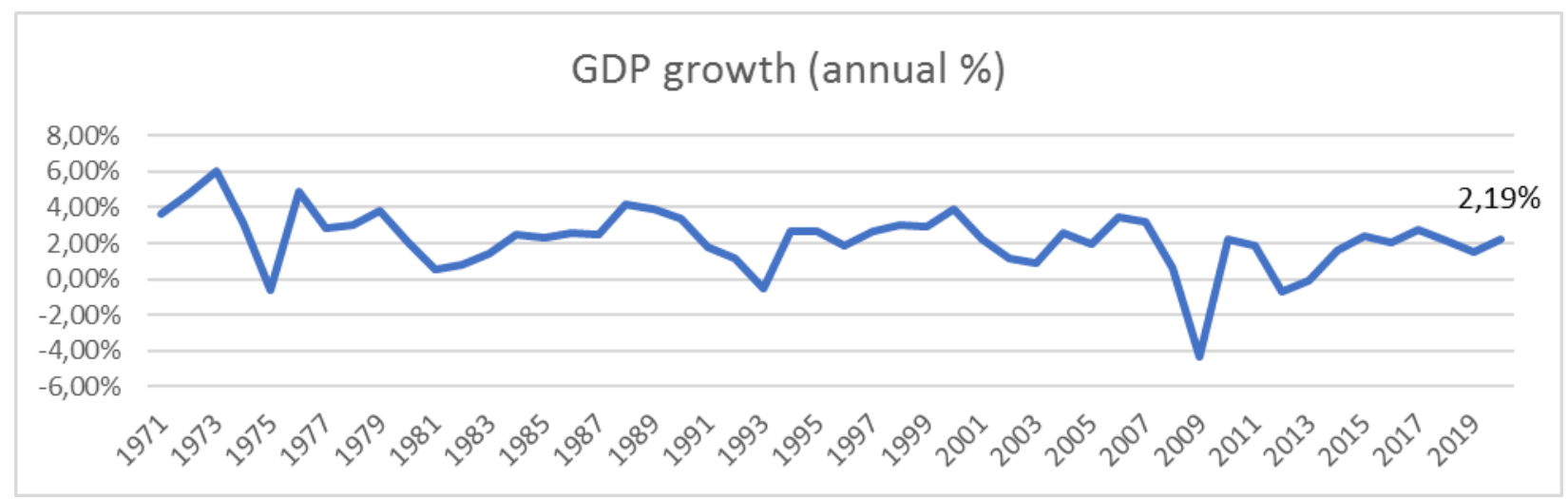

Figure 1. GDP growth EU (annual \%)

Source: authors after The World Bank (2020)

The development of the European Union is based on the concept of "green development", in which "green" industries, goods and services contribute to efforts to limit the negative effects on the environment, stimulating the creation of new jobs and fostering the transition of traditional industry to recording performance in terms of environmental issues.

The OECD defines the concept of "green development" as a model that aims to encourage growth and development, while avoiding unsustainable pressure on the quality and quantity of natural assets, ensuring that these assets continue to provide the environmental resources on which the well-being of the population is based (OECD, 2020).

At the level of the European Union there are several states that have adopted the concept of "green development". Table 1 shows examples of European government initiatives aimed to increase development through environment protection. 


\section{Table 1. Selection of government initiatives for "green development"}

\begin{tabular}{|c|c|c|c|}
\hline Nr. & Country & Name & Observations \\
\hline 1 & Germany & $\begin{array}{l}\text { Renewable energy } \\
\text { pioneer }\end{array}$ & $\begin{array}{l}\text { The National Strategy for Sustainable } \\
\text { Development (2002) defines targets for } 21 \\
\text { different sectors of activity. In } 2010 \text {, } \\
\text { approximately } 17 \% \text { of the electricity supply } \\
\text { was provided from renewable sources, } \\
\text { exceeding the target of } 12.5 \% \text {. }\end{array}$ \\
\hline 2 & Ireland & $\begin{array}{l}\text { A comprehensive green } \\
\text { expenditure framework }\end{array}$ & $\begin{array}{l}\text { Ireland's National Development Plan (2007- } \\
2013 \text { ) sets out indicative financial allocations } \\
\text { for investment priorities aimed at strengthening } \\
\text { economic competitiveness and ensuring a better } \\
\text { quality of life. It also brings together different } \\
\text { investment policies in one document. The } \\
\text { chapters on the environment deal with the } \\
\text { following sectors: transport, waste } \\
\text { management, climate change, research and } \\
\text { sustainable energy. }\end{array}$ \\
\hline 3 & $\begin{array}{l}\text { Baltic } \\
\text { countries } \\
\text { (Sweden, } \\
\text { Finland) }\end{array}$ & Using green procurement & $\begin{array}{l}\text { Public procurement accounts for about } 16 \% \text { of } \\
\text { the GDP of the Nordic countries, and for some } \\
\text { product groups, the public sector is the largest } \\
\text { buyer. As a result, all Nordic countries have } \\
\text { recently issued national action plans and } \\
\text { developed legislation to ensure the } \\
\text { sustainability of public procurement. }\end{array}$ \\
\hline 4 & $\begin{array}{l}\text { United } \\
\text { Kingdom* }\end{array}$ & $\begin{array}{l}\text { The Green Investment } \\
\text { Bank }\end{array}$ & $\begin{array}{l}\text { The UK aimed to open a bank in } 2012 \text { with } £ \\
3 \text { bn from the public budget to provide funding } \\
\text { for low-carbon projects that could be too risky } \\
\text { or have long-term returns for the market to } \\
\text { invest in. }\end{array}$ \\
\hline
\end{tabular}

Source: authors after OECD Green Growth Papers 2012, Green Growth and Environmental Governance in Eastern Europe, Caucasus, and Central Asia, OECD Publishing, Paris, page 23-25

* United Kingdom is on the way to leave the European Union

Policies that promote environmental protection through environmentally friendly measures must be based on solid analysis, embedded in a clear conceptual framework for all Member States. In line with this objective, international bodies have chosen indicators in the following four areas, with a massive impact on ensuring development in close correlation with environmental protection:

- Natural assets, questions the size of resources in a space and the perceived value of natural capital;

- Environment and resource productivity, identifies production and consumption deficiencies and emphasizes the impact on the environment of the use of resources;

- The environmental dimension of human well-being, shows how important the environment is for people's lives;

- Economic opportunities and political answers, factor that shows how efficient a certain policy is in the transition to the green economy (OECD, Green Growth and Environmental Governance in Eastern Europe, Caucasus, and Central Asia, 2012). 
Increasing attention to environmental issues contributes to ensuring development through the benefits of this approach, compared to the challenges that people feel in terms of environmental issues:

- Productivity: green development can increase productivity by reducing waste and energy consumption and using the resources available for the use of those elements in higher valueadded areas. For example, the value of fuel savings from investments in low-carbon energy systems has been estimated at US \$ 112 trillion between 2020 and 2050 (International Energy Agency, 2010);

- Innovation: sustainable development, through better policies and transparent framework conditions, offers opportunities for innovation both from existing companies in the market and from new organizations built on sustainable principles;

- New jobs: Investments in environmentally friendly activities will generate many jobs, which some European Union governments have seen in the last decade and which they have tried to capitalize on. It is estimated that there is great potential for more than 1 million new jobs to expand into renewable energy, including 515000 jobs in agriculture and the supply of biomass fuels (ECOTEC Research and Consulting Limited, 2008). At the same time, there is a risk that some current jobs will be exposed, so it is important that Member States take measures to allocate workers to expanding sectors and companies that engage in cleaner production alternatives or provide environmental services;

- New markets: the creation of new markets can be improved by stimulating demand for green technologies, goods and services and generating new job opportunities;

- Trust: sustainable development strategies and objectives can increase investor confidence through increasing predictability and stability in how governments deal with major environmental issues;

- Stability/predictability: green growth leads to more balanced macroeconomic conditions, lower resource price volatility and fiscal consolidation by reviewing the structure and efficiency of public spending and increasing revenue by setting the price of pollution (OECD, Green Growth and Environmental Governance in Eastern Europe, Caucasus, and Central Asia, 2012).

\section{MATERIALS AND METHODOLOGY}

In order to ensure the methodological transparency of this bibliometric analysis focused on the relationship between economic development and environmental protection, the authors applied a systematic review process in close accordance with other publications of this type (Popa \& Gora, 2020; Cicea et al., 2019; Gora, 2019; Marinescu \& Cicea, 2018).

After establishing the purpose of the study, the first step was to select the database with publications based on which we can develop a data set suitable for bibliometric analysis. For this purpose, the WoS (Web of Science) database was chosen and used, to select the scientific papers that contain the two terms to be analysed, our arguments being the compatibility with the analysis software, but also the exhaustiveness of the data set.

After choosing the database, the third step involved the documents selection taking into account the English language. In this way, 1401 documents were identified in the mentioned database, which simultaneously deal with the phrases "environmental protection" and "economic development". The year 2020 was removed from the analysis because it is not a full year, and the analysis interval was 2000-2019; subsequently, only "article", "conference paper", "book chapter" and "review" documents were considered. As a result, 1110 documents remained to be analysed in order to perform the bibliometric analysis.

The methodology of the paper was based on the observance of two essential criteria specific to this working time, namely the coverage and accuracy of the data. 
Coverage refers to the extent to which the sources processed by a database cover the scientific literature written in a field. As such, the coverage does not have to be biased towards certain countries, languages or publishers, and this is respected by searching for articles in the Scopus database.

In terms of data accuracy, this refers to the absence of inconsistencies and misspellings of author names or a lack of standardization in terms of journal titles and affiliations. This is respected by the criteria on the basis of which documents were selected as the basis for scientific research on the one hand, and on the other hand the WoS database has positive feedback from many authors because it uses an algorithm to minimize errors in as far as authors and institutions are concerned. Finally, the analysis that are to be performed following the stated methodology are:

- STAGE 1 - Analysis of the geographical and temporal distribution of scientific production in the field - by going through this stage we want to highlight in which geographical areas, respectively in which period the concepts analysed in this paper were in the attention of the general public to address all implications the relationship between economic development and environmental protection;

- STAGE 2 - Semantic analysis of keywords - this stage aims to identify the correlations between economic development and environmental protection in terms of words derived from the two concepts, respectively which are those subdomains that are influenced by publications and how close this influence is;

- STAGE 3 - Identifying significant clusters based on keywords - through this stage we are trying to see the areas of interest for research aimed at achieving economic development in correlation with environmental protection. Moreover, this stage is essential from the perspective of the fact that we will be able to observe how the concepts are grouped according to the relationship between them, so that even if at the first glance we can say that there is a correlation between economic development and environmental protection, through this paper we will be able to explain this correlation through the papers published by specialists, respectively the uses of concepts in the same papers.

To carry out the research, documents were downloaded from the WoS database containing the following characteristics: title, year of publication, authors, abstract, keywords; all this information was used in the VOSviewer program.

\section{RESULTS AND DISCUSSION}

In accordance with the phases above outlined, we will first analyse the temporal and the geographical spread of the scientific production. Thus, using the WoS database, we obtained the following annual distribution of documents, graphically represented in Figure 2. The 2000-2008 period of time reflects a relatively hesitating and long beginning of the research regarding economic development and environmental protection. However, since 2009 till 2019, the number of papers included in the main flow of publications, almost doubled, showing the growing interest for the concerned theme. What is more, the last five years of the analysed period account for almost $62 \%$ of the total number of the articles considered in this study.

Looking closer at the graphical representation within Figure 2, we can observe three turning points in the literature specific to economic development and environmental protection. The first milestone is at the level of 2008, the second one is at the end of 2014 and the third one is linked to 2018. Each point reflects an increase in the scientific production, which is directly connected to the researchers' interest for this theme and indirectly related to national, regional and global policies that promote environmental protection. 


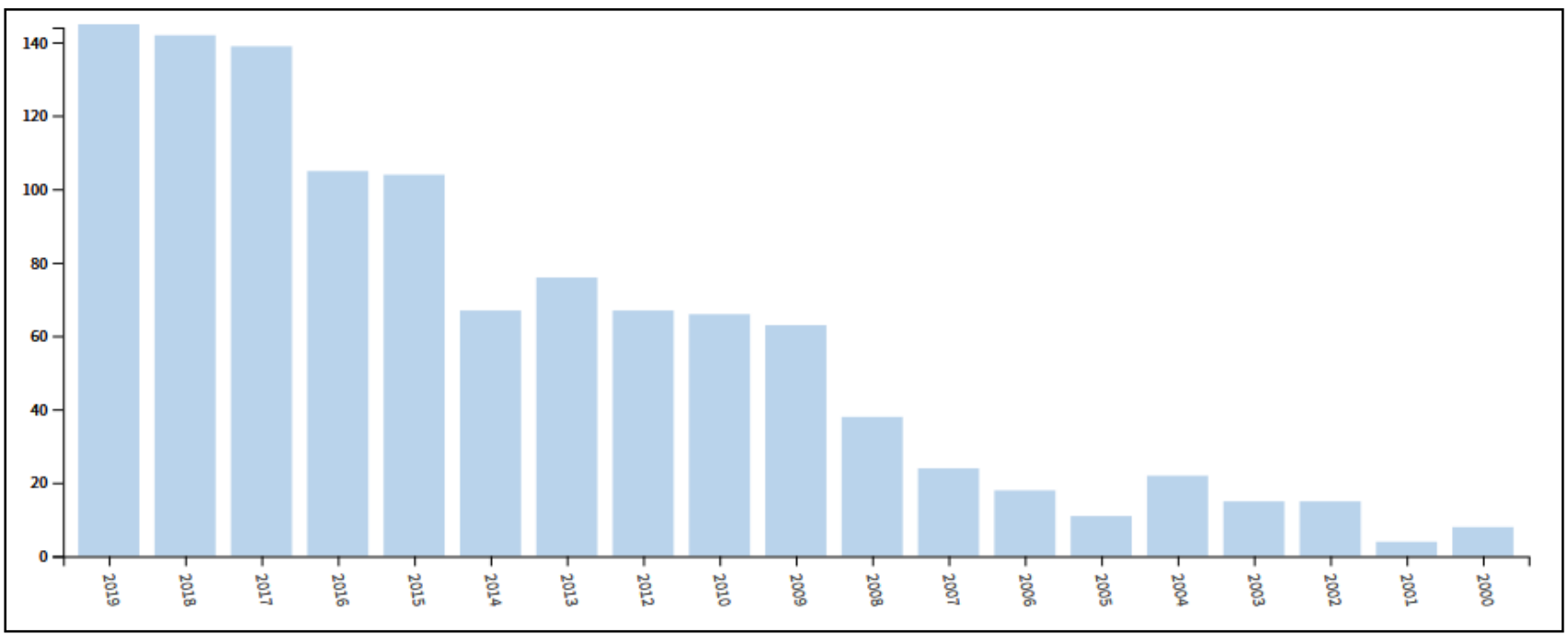

Figure 2. Timeline of the scientific production

Source: authors using WoS database

Going further, the geographical distribution of the scientific production will be analysed, by studying the affiliation of the first author or, by the case, of the corresponding author. Figure 3 is designed as a tree-map. Each branch contains the number of authors affiliated to an institution or organization from a specific country, so the size of a "leaf node" (the rectangle) is proportional to this number.

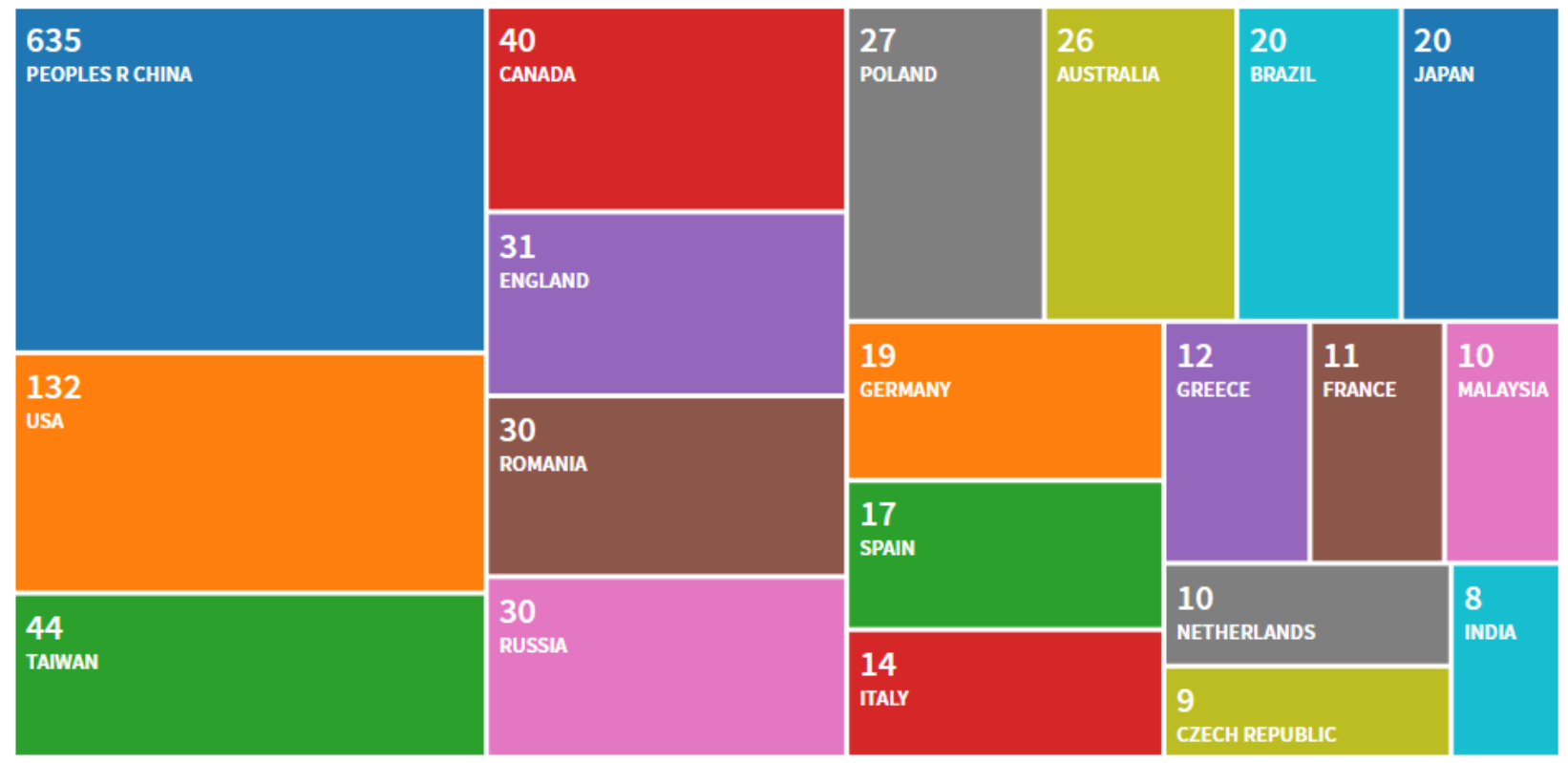

Figure 3. First author or corresponding author's affiliation by country

Source: authors using WoS

As the tree-map confirms, the main source of the scientific production is the People's Republic of China, accounting for more than a half of the analysed documents with 635 authors. It is followed by USA and Taiwan with 132 and 44 authors. What is more, this first three countries are home for around $55 \%$ of the total number of authors (1145). 
In terms of keywords' analysis, this was undertaken with help of VOSViewer. In order to obtain valid results, the authors removed from the analysis the two collocations after which the Web of Science database was queried: "environmental protection" and "economic development". The keywords' occurrences for the 1110 articles subject to this analysis are presented in the table below.

Table 2. Top 20 keywords ranked after occurrences

\begin{tabular}{|l|l|c|c|}
\hline $\begin{array}{l}\text { Nr. } \\
\boldsymbol{c r t} .\end{array}$ & Keyword & Occurrences & Total link strength \\
\hline $\mathbf{1}$ & Sustainable development & 138 & 161 \\
\hline $\mathbf{2}$ & China & 100 & 222 \\
\hline $\mathbf{3}$ & Sustainability & 65 & 128 \\
\hline $\mathbf{4}$ & Management & 61 & 126 \\
\hline $\mathbf{5}$ & Environment & 61 & 106 \\
\hline $\mathbf{6}$ & Policy & 49 & 109 \\
\hline $\mathbf{7}$ & Pollution & 46 & 117 \\
\hline $\boldsymbol{8}$ & Energy & 43 & 107 \\
\hline $\mathbf{9}$ & CO2 emissions & 42 & 151 \\
\hline $\mathbf{1 0}$ & Model & 40 & 93 \\
\hline $\mathbf{1 1}$ & Impact & 35 & 94 \\
\hline $\mathbf{1 2}$ & Growth & 34 & 113 \\
\hline $\mathbf{1 3}$ & Climate change & 29 & 56 \\
\hline $\mathbf{1 4}$ & Economic-growth & 28 & 106 \\
\hline $\mathbf{1 5}$ & Impacts & 28 & 61 \\
\hline $\mathbf{1 6}$ & Urbanization & 27 & 69 \\
\hline $\mathbf{1 7}$ & Efficiency & 26 & 54 \\
\hline $\mathbf{1 8}$ & Emissions & 25 & 68 \\
\hline $\mathbf{1 9}$ & Conservation & 25 & 37 \\
\hline $\mathbf{2 0}$ & Air-pollution & 23 & 60 \\
\hline & & $V 0 S \mathrm{i}$ & \\
\hline
\end{tabular}

Source: authors using VOSViewer

Table 2 also reveals the total link strength for each keyword, showing in this way the keyword's power to connect to other identified keyword. For instance, "sustainable development" appears 138 times within the articles and creates 161 links with other keywords, while "China" appears 100 times, but manages to connect more, as it reports 222 links. The least connected keyword is "conservation".

An even more suggestive situation was generated in VOSViewer based on the grouping of keywords in clusters (out of a total of 4406 keywords, only those that have a frequency of occurrence of at least 15 times, were considered, namely 39 keywords). This grouping is visually designed as a map which includes each cluster, the nodes and the branches linking the nodes.

The largest cluster is the red one, composed out of 15 keywords, followed by the green one with 14 nodes and by the blue one with 10 nodes. The size of each node is given by the number of occurrences of that keyword, so larger a bubble, greater the number of keyword's occurrences. The position of each keyword within the network represented in Figure 4, shows how likely it is to find two keywords in the same context. For instance, "indicators" is positioned as a keyword in the upper half of the network, while ,climate change” appears in the lower half of the map, so their connection within articles is very low or perhaps never found together in the discussed context. 


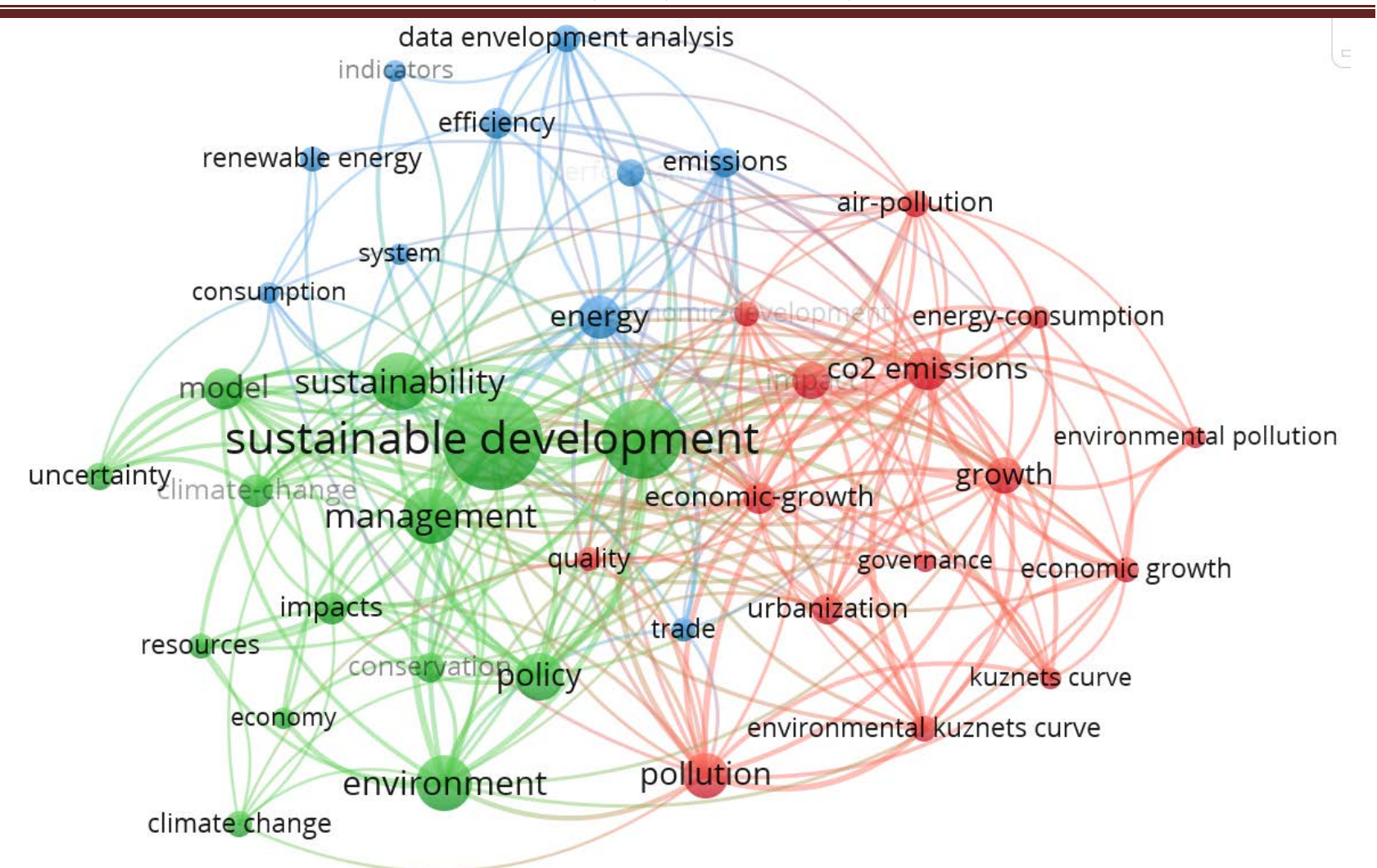

Figure 4. Grouping keywords in clusters

Source: authors using VOSViewer

Looking once again at the network shown in Figure 4, we can observe the centrality of "sustainable development" and "China" as keywords, meaning that the importance of these two keywords within the research field of environmental protection and economic development, is high. "China" is the single keyword from the map (in green cluster) referring to a country, while "data envelopment analysis" is the single collocation (in blue cluster) bringing into attention a performance assessment method. The red cluster holds two collocations referring to the relationship between the economic development of a society and its impact within the environment; "Kuznets curve" and "environmental Kuznets curve" describe in theory that the level of environmental degradation reduces if a society achieves a certain level of development.

If we examine the keywords assigned to each cluster, we can observe that they tend to highlight specific features or related meaningful concepts related to the relationship between environmental protection and economic development. The blue cluster refers mainly to performance of the energy systems which certainly influences environmental protection, while the red cluster focuses on the societies' growth which also impacts the environment. The green cluster is more complex as it seems to include methods to act in a sustainable manner.

\section{CONCLUSIONS}

Within this paper, the construction of the graphs has revealed salient features of economic development - environmental protection research in time. By grouping keywords in clusters we were able to see the links between different terms existing in the same context, revealing that it is a big possibility to have a lower correlation between a phenomenon such as ,climate change” and a way to measure the impact of the phenomenon like the "indicators" term. Taking this situation into account, a further paper can take into consideration the development of a network of indicators that accurately describe the „climate change”. Moreover, based on the Figure 4, there are three types of 
concepts that can have an influence on the relationship between economic development and environmental protection: the performance of the energy systems which can be translated through innovation concept, the society and the methods used by the society to achieve green development. Taking into account Figure 2, we can say that the topic of the paper is at the beginning stage, so there is enough room to bring about tremendous improvements of the research in the field, between 2014 and 2019 being published almost $62 \%$ of the total number of the articles considered in the present paper. It is also important to mention that year by year this topic is brought to people's attention through a scientific form, which contributes to the awareness of the effects that people's activities have on the environment. Moving at the Figure 3, there is clear for us that the topic of our paper is a central one in China (635), this country representing the main source of the scientific production. On the other hand, we can highlight that there are also countries from European Union which are interested in studying this topic, mentioning here England (31), Romania (30), Poland (27), Germany (19), Spain (17), etc.

Even though the authors explained in detail the methodology used within this paper, the study has some limitations. First of all, the authors used only WoS database to obtain articles. A similar analysis could be conducted using other databases, such as Scopus, which may influence the number of selected articles and provide other query options. Second, each tool used to arrange results in a specific way (see keywords map or tree-map) has its own configuration. It depends only on the ability of authors to learn how to use other software tool too. Third, the relationship between environmental protection and economic development, has not been studied also in time, to highlight sub-periods when specific issues were in the light of researchers' attention. This may constitute a future research direction.

\section{Acknowledgment}

This paper is a result of the research conducted through the 2020-2023 Doctoral advanced research program at The Bucharest University of Economic Studies.

\section{REFERENCES}

Ansuategi, A. (2003). Economic Growth and Transboundary Pollution in Europe: An Empirical Analysis. Environmental and Resource Economics, 305-310.

Chao, B., \& Wang, S. (2017). Opening up, international trade, and green technology progress in China. Journal of Cleaner Production, 1002-1012.

Chandran, V., \& Tang, C. (2013). The impacts of transport energy consumption, foreign direct investment and income on $\mathrm{CO} 2$ emissions in ASEAN-5 economies. Renewable \& Sustainable Energy Reviews, 445-453.

Cicea, C., Marinescu, C., Albu, C.F., \& Balan, P.D (2019). Applying Bibliometric Mapping and Clustering on Research regarding Biomass related Innovation. in Proceedings of 33rd IBIMA Conference: 10-11 April 2019, (pp. 2404-2419). Granada, Spain.

Dinda, S. (2004). Environmental Kuznets curve hypothesis: a survey. Ecological Economics, 431455.

ECOTEC Research and Consulting Limited. (2008). Renewable Energy Sector in the EU its Employment and Export Potential. Birmingham: Ecotec. Retrieved from https://ec.europa.eu/environment/enveco/eco_industry/pdf/ecotec_renewable_energy.pdf

Eurostat. (2020a). Energy Statistics - an overview. Retrieved from eurostat: https://ec.europa.eu/eurostat/statistics-explained/index.php/Energy_statistics__an_overview\#Final_energy_consumption

Eurostat. (2020b). Eurostat. Retrieved from https://appsso.eurostat.ec.europa.eu/nui/submitViewTableAction.do 
Gora, A. A. (2019). The Link Between Decision Making Process and Performance: A Bibliometric Analysis. Management and Economics Review, 4(2), 177-191.

International Energy Agency. (2010). Energy Technology Perspectives. Paris: OECD/IEA.

Jalil, A., \& Mahmud, S. (2009). Environment Kuznets curve for CO emissions: a cointegration analysis for China. Energy Policy, 5167-5172.

Marinescu, C., \& Cicea, C. (2018). A Bibliometric Analysis of the International Management Conference Proceedings' Papers. In Proceedings of the International Management Conference, 12(1), (pp. 293-306) Bucharest, Romania.

OECD. (2012). Green Growth and Environmental Governance in Eastern Europe, Caucasus, and Central Asia. Paris: OECD Publishing. doi:10.1787/5k97gk42q86g-en

OECD. (2020). OECD. Retrieved from https://www.oecd.org/greengrowth/

Pachauri, R. (2008). Battling Climate Change by Promoting Environmentally Sustainable Development. Achieving Sustainable and Promoting Development Cooperation - Dialogues at the ECOSOC, 17-20. Retrieved from https://www.un.org/en/ecosoc/docs/pdfs/fina_0845773.pdf

Popa, I., \& Gora, A. A. (2020). Bibliometric Analysis of the Links between Knowledge Management and Competitive Advantage. In The Best Romanian Management Studies 20172018, pp. 65-83. Trivent Publishing, https://www.triventpublishing.eu/books/romanianmanagementstudies/4.\%20Ion\%20Popa,\%20Ana\%20Alexandra \%20Gora.pdf

Sun, J., Wang, J., Wang, T., \& Zhang, T. (2019). Urbanization, economic growth, and environmental pollution. Partial differential analysis based on the spatial Durbin model. Management of Environmental Quality: An International Journal, 483-484. doi:10.1108/MEQ05-2018-0101

The World Bank. (2020). The World Bank. Retrieved from https://data.worldbank.org/indicator/NY.GDP.MKTP.KD.ZG?end=2019\&locations=EU\&start $=1971 \&$ view $=$ chart

Youssef, A., Hammoudeh, S., \& Omri, A. (2016). Simultaneity modeling analysis of the environmental Kuznets curve hypothesis. Energy Economics, 266-274. 